\title{
HVAC Transmission System for Offshore Wind Power Plants Including Mid-cable Reactive Power Compensation: Optimal design and comparison to VSC-HVDC transmission
}

\author{
Jovana Dakic, Marc Cheah-Mane, Member, IEEE, Oriol Gomis-Bellmunt, Senior Member, IEEE \\ and Eduardo Prieto-Araujo, Member, IEEE,
}

\begin{abstract}
The design distance of offshore wind power plants connected through HVAC transmission systems might be extended due to the introduction of mid-cable reactors for reactive power compensation purposes and the latest developments of AC cables for higher voltages. Therefore, the applicability limits between HVAC and HVDC systems must be revised. This paper analyzes the contribution that mid-cable reactive power compensation has on increasing the distance limits of HVAC transmission systems. A methodology is developed to determine an optimal design of such transmission systems. In this methodology, cost of power losses and reactors are minimized for multiple wind speed conditions. As a result, the optimal HVAC voltage level and the optimal number of reactors and their location are determined for different OWPP rated powers and distances. Also, the final transmission system is selected between HVAC and HVDC equivalent configurations based on total costs.
\end{abstract}

Index Terms-HVAC, HVDC, Offshore Wind Power Plant, Optimization, Reactive Power Compensation, Transmission System

\section{INTRODUCTION}

$\mathbf{O}$ FFSHORE wind power generation is experiencing a significant expansion during the recent years, especially in Europe [1]. A number of transmission system configurations have been proposed to integrate large Offshore Wind Power Plants (OWPPs) to shore based on efficient, reliable and costeffective designs. Configurations based on High Voltage AC (HVAC) and High Voltage DC (HVDC) are currently considered for offshore transmission systems. HVDC configurations are traditionally used for long distances, since reactive power is not generated and costs of power losses can be reduced compared to HVAC options. However, HVAC configurations are currently being considered for longer distances, including midcable reactive power compensation and recently developed AC cables of higher voltages. In particular, Hornsea One and Two are current projects that include such mid-cable reactive power compensation [2]. Therefore, the selection between HVDC and HVAC configurations for long distances should be revised.

The authors are with the Centre d'Innovació Tecnològica en Convertidors Estàtics i Accionaments, Departament d'Enginyeria Elèctrica, Universitat Politècnica de Catalunya, Barcelona 08028, Spain. E-mail: jovana.dakic@upc.edu. Marc Cheah-Mane and Eduardo Prieto-Araujo are Lecturers of the Serra Húnter programme. Oriol Gomis-Bellmunt is also an ICREA Academia researcher.

This project has received funding from the European Union's Horizon 2020 research and innovation programme under the Marie Sklodowska-Curie grant agreement no. 765585. This document reflects only the author's views; the European Commission is not responsible for any use that may be made of the information it contains.
The installation of mid-cable reactors represents a potential solution to improve reactive power compensation [3], [4]. The distribution of reactive power along a non-loaded cable is shown in Fig. ??, where different locations and numbers of reactors are presented [3]. It is clear that if reactors are installed in the middle or equally distributed at both ends of the cables the maximum value of reactive power, i.e. the loading of the cable, is reduced, as seen in Fig. ??(b) and Fig. ??(c). Also, combining reactors at both ends of the cables with a mid-cable reactor further decreases the reactive power down to $75 \%$ of the maximum value compared to installing a single reactor, as shown in Fig. ??(a) and Fig. ??(d) [5]. Then, even though the cost of installation of an offshore platform for a mid-cable reactor is high, the potential optimization of reactive power flows and the reduction of power losses can be beneficial to reduce the operation costs.

Few studies are focused on the analysis of reactive power compensation using reactors for long distance HVACconnected OWPPs. In [6], optimization of reactive power compensation is presented by minimizing cost of power losses and reactors and considering several rated powers, voltages and transmission distances. However, only two reactors located at both ends of the cable are analyzed. Also, the improvement of the active power transfer capability over long distances including mid-cable reactors and comparison with HVDC configurations is presented in [7]. However, the optimal sizing and location of compensation reactors is not addressed.

This paper presents an optimal design for the transmission system of HVAC-connected OWPPs, where the contribution of mid-cable reactive power compensation is studied in detail. The analysis and optimization of an HVAC offshore transmission system considering different locations and number of reactors has not been fully investigated in the literature, especially when mid-cable reactors included. Therefore, the contributions of this paper can be summarized as follows:

- A methodology is presented to select the optimal configuration for an HVAC offshore transmission system. This includes a minimization of reactor and power losses cost based on multiple wind speed conditions. In addition, this methodology compares the optimal HVAC configuration with an equivalent HVDC option.

- Selection between HVAC and HVDC configurations and selection of the number of reactors in HVAC options is defined for a range of distances and OWPP rated powers. 
Initially, a power flow model and a cost model are defined for HVAC and HVDC transmission systems, Then, the design methodology is developed based on a set of voltage levels, reactor locations and number of reactors. As a result, this methodology is applied for several OWPPs rated powers and distances to shore and two specific case studies are presented in detail in order to understand the influence of the mid-cable reactor on the break-even distance.

\section{DESCRIPTION OF TRANSMission CONFIGURATIONS}

The HVAC and HVDC transmission systems considered in the paper are described in this Section and shown in Fig. ??.

\section{A. HVAC transmission system}

The configuration of an HVAC transmission system for offshore wind power plants (OWPPs) is shown in Fig. ??(a) and Fig. ??(a). This configuration is based on two substations interconnected with cross-linked polyethylene (XLPE) cables. The substations include power transformers, gas or air insulated switchgears and reactive power compensation equipment. Offshore transformers are used to step up the voltage from the collector grid of an OWPP, which operates at medium voltage (33 or $66 \mathrm{kV})$ to the transmission level $(110,150$ and $220 \mathrm{kV})$. Also, onshore transformers are used to step up the voltage to the onshore grid operating level (220-400 kV). The preferred transformer topology is based on two transformers in parallel, which are rated at $60 \%$ of the OWPP nominal power in order to increase power export availability [8]. In this case, three-core XLPE cables are considered for the transmission system, which has been recently used in projects Hornsea One and Two [2] due to reduced power losses and less installation costs [9]. A number of cable circuits are connected in parallel, which depends on the rated power of OWPP and the transmission voltage. Also, reactors are used along the cables in order to compensate reactive power, which leads to a reduction of power losses and provides further voltage control. In particular, a maximum of three reactors are considered, where all possible locations and combinations are specified in Fig. ??.

\section{B. HVDC transmission system}

In this paper, a Voltage Source Converter HVDC (VSCHVDC) topology based on symmetrical monopolar configuration is considered as shown in Fig. ??(b) and Fig. ??(b). This configuration consists of two VSCs interconnected with transmission DC cables, which are rated up to $525 \mathrm{kV}$ [10]. The converters are connected to each AC side through transformers, which are the same as in Section II-A.

\section{Modeling of Transmission CONFIGURATIONS}

Transmission systems are modeled for steady-state analysis in order to calculate power losses. Offshore wind power plants are represented considering the operation at different wind speeds. Also, the cost modeling of all components is described in this Section based on expressions and data from the literature.

\section{A. HVAC transmission system}

The model presented in this Section is used to calculate total costs of the HVAC transmission system as well as to comply with the voltage and current operational limits. As a result, detailed models of the components, a power flow formulation and cost functions are presented in the following subsections:

1) Cable model: Long transmission cables are modeled using a formulation based on hyperbolic functions [11], which defines the following expressions:

$$
\begin{gathered}
{\left[\begin{array}{l}
\underline{V}_{I} s \\
\underline{I}_{s}
\end{array}\right]=\left[\begin{array}{cc}
\cosh (\underline{\theta}) & \underline{Z}_{c} \sinh (\underline{\theta}) \\
\sinh (\underline{\theta}) / \underline{Z}_{c} & \cosh (\underline{\theta})
\end{array}\right]\left[\begin{array}{l}
\underline{V}_{r} \\
\underline{I}_{r}
\end{array}\right]} \\
\underline{Z}_{c}=\sqrt{\frac{\underline{Z}}{\underline{Y}} ; \quad \underline{\theta}=l \sqrt{\underline{Z} \underline{Y}}} \\
\underline{Z}=R+j \omega L ; \quad \underline{Y}=j \omega \frac{C}{2}
\end{gathered}
$$

where $\underline{V}_{s}$ and $\underline{I}_{s}$ are voltages and currents at the sending end terminal, $\underline{V}_{r}$ and $\underline{I}_{r}$ are voltages and currents at the receiving end terminal, $\underline{Z}_{c}$ is the characteristic impedance, and $\underline{\theta}$ is the characteristic angle. The cable parameters are defined as per unit length in (3), where $R$ is the resistance, $L$ is the inductance, $C$ is the capacitance and $l$ is the cable length.

As a result, cables are represented with an equivalent $\pi$ section, shown in Fig. ??(a), where $\underline{Z}_{\pi}$ and $\underline{Y}_{\pi}$ are defined as:

$$
\begin{gathered}
\underline{Z}_{\pi}=\underline{Z}_{c} \sinh (\underline{\theta})=\underline{Z l} l \frac{\sinh (\underline{\theta})}{\underline{\theta}} \\
\underline{Y}_{\pi}=\frac{\tanh (\underline{\theta} / 2)}{\underline{Z}_{c}}=\frac{\underline{Y} l}{2} \frac{\tanh (\underline{\theta} / 2)}{\underline{\theta} / 2}
\end{gathered}
$$

It should be noted that this formulation provides higher accuracy than equivalent $\pi$ section directly obtained from cable parameters [11].

2) Transformer model: The transformer is represented as an equivalent circuit referred to the transmission system side, as shown in Fig. ??(b). The equivalent impedance $\underline{Z}_{t r}$ and admittance $\underline{Y}_{t r}$ of the transformer are expressed as:

$$
\begin{gathered}
\underline{Z}_{t r}=R_{t r}+j X_{t r} ; \quad \underline{Y}_{t r}=G_{t r}-j B_{t r} \\
R_{t r}=P_{C u}^{l o s s}\left(\frac{U_{r-t r}}{S_{r-t r}}\right)^{2} ; X_{t r}=\sqrt{\left(u_{k} \frac{U_{r-t r}^{2}}{S_{r-t r}}\right)^{2}-R_{t r}^{2}} \\
G_{t r}=\frac{P_{F e}^{l o s s}}{U_{r-t r}^{2}} ; \quad B_{t r}=i_{o} \frac{S_{r-t r}}{U_{r-t r}^{2}}
\end{gathered}
$$

where $P_{C u}^{\text {loss }}$ are the copper losses, $U_{r-t r}$ is the rated voltage of the transformer at the transmission system side, $S_{r-t r}$ is the rated power of the transformer, $P_{F e}^{\text {loss }}$ are the iron losses, $u_{k}$ is the short circuit voltage and $i_{o}$ is the open circuit current.

3) Shunt reactor model: Reactors are modeled with admittance $\underline{Y}_{l}=1 /\left(j \omega L_{r}\right)$ where $L_{r}$ is the equivalent inductance of the reactor.

4) Main grid: The grid is modeled with a Thévenin equivalent, where $\underline{U}_{g}$ is the Thévenin voltage and $\underline{Z}_{g}=R_{g}+j X_{g}$ is the Thévenin impedance. This grid equivalent is calculated from the short circuit ratio $(\mathrm{SCR})$ and $X_{g} / R_{g}$ ratio. 
5) Power flow formulation: The power flow model of the HVAC transmission system is defined in per-unit system, as shown in Fig. ??. In case of a multiple number of cable circuits and transformers, equivalent impedances and admittances represent the aggregation of such components in parallel.

Then, the power flow equations in per-unit system are:

$$
\begin{aligned}
\underline{u}_{1} \underline{i}_{1}^{*} & =p_{\text {owf }}+j q_{\text {owf }} \\
\underline{u}_{1} & =\underline{u}_{2}+\underline{z}_{t r} \underline{i}_{2} \\
\underline{i}_{1} & =\left(\underline{y}_{t r}+\underline{y}_{l}\right) \underline{u}_{1}+\underline{i}_{2} \\
\underline{u}_{2} & =\underline{u}_{3}+\underline{z}_{\pi 1} \underline{i}_{3} \\
\underline{i}_{2} & =\left(\underline{y}_{\pi 1}+\underline{y}_{l}\right) \underline{u}_{2}+\underline{i}_{3} \\
\underline{i}_{3} & =\left(\underline{y}_{\pi 1}+\underline{y}_{l}+\underline{y}_{\pi 2}\right) \underline{u}_{3}+\underline{i}_{4} \\
\underline{u}_{3} & =\underline{u}_{4}+\underline{z}_{\pi 2} \underline{i}_{4} \\
\underline{i}_{4} & =\left(\underline{y}_{\pi 2}+\underline{y}_{l}\right) \underline{u}_{4}+\underline{i}_{5} \\
\underline{u}_{4} & =\underline{u}_{5}+\underline{z}_{t r} \underline{i}_{5} \\
\underline{i}_{5} & =\left(\underline{y}_{t r}+\underline{y}_{l}\right) \underline{u}_{5}+\underline{i}_{g} \\
\underline{u}_{5} & =\underline{u}_{g}+\underline{z}_{g} \underline{i}_{g}
\end{aligned}
$$

The power losses of the HVAC transmission system represent ohmic losses coming from cables and transformers. As a result, the power losses in MW can be expressed as:

$$
P_{\text {loss }-A C}=\left(p_{\text {owf }}-p_{g}\right) \cdot S_{b}=\left(p_{o w f}-\operatorname{Re}\left\{\underline{u}_{5} \underline{i}_{g}^{*}\right\}\right) \cdot S_{b}
$$

where $p_{\text {owf }}$ is the active power coming from the OWPP, $p_{g}$ is the active power delivered to the grid and $S_{b}$ is the base value of the power.

6) Cost modeling: Cost functions are presented for $\mathrm{AC}$ cables, switchgears, transformers, reactors, AC substation platform and power losses.

The cost of AC cables is expressed as [12]:

$$
C_{c b-A C}=\frac{\left(A+B e^{C S_{r-c b}}+D\right) \cdot(9 n+1)}{10 E} \cdot l
$$

where $A, B, C, D$ and $E$ are coefficients defined in Table I, which are dependent on the cable voltage [13], [14], $S_{r-c b}$ is the rated apparent power of the cable in MVA and $l$ is the cable length in $\mathrm{km}$.

The cost of switchgears is calculated as [15]:

$$
C_{\text {gis }-A C}=0.0117 \cdot U_{A C-N}+0.0231
$$

where $U_{A C-N}$ is the nominal transmission voltage in $\mathrm{kV}$.

The cost of transformers is obtained as [16]:

$$
C_{t r}=0.0427 \cdot S_{r-t r}^{0.7513}
$$

where $S_{r-t r}$ is the rated power of the transformer in MVA.

The cost of reactors is derived from [6], [15], [17] as:

$$
C_{\text {react }}=K \cdot Q_{l}+P
$$

where $K$ and $P$ are the constant values defined in Table II, which are dependent on the location of reactor, $Q_{l}=Y_{l}$. $U_{A C-N}^{2}$ is the reactive power compensated by the reactors.

The substation platform cost is calculated as [14], [18]:

$$
C_{s s-A C}=2.534+0.0887 \cdot P_{o w f-N}
$$

where $P_{o w f-N}$ is the nominal power of the offshore wind power plant in MW.

The operation cost of $\mathrm{AC}$ power losses is expressed as:

$$
C_{\text {loss }-A C}=8760 \cdot t_{\text {owf }} \cdot C_{E} \cdot P_{\text {loss }-A C}
$$

where $t_{\text {owf }}$ is the life time of the wind power plant in years and $C_{E}$ is the cost of energy in $€ / \mathrm{MWh}$. The expected life time is to be at least 25 years with the possibility to extend by up to an additional 25 years [19].

TABLE I

COEFFICIENTS FOR XLPE SUBMARINE AC CABLES [13], [14]

\begin{tabular}{c|ccccc}
\hline & $30 \mathrm{kV}$ & $70 \mathrm{kV}$ & $150 \mathrm{kV}$ & $220 \mathrm{kV}$ & $400 \mathrm{kV}$ \\
\hline $\mathrm{A}$ & 0.411 & 0.688 & 1.971 & 3.181 & 5.8038 \\
$\mathrm{~B}$ & 0.596 & 0.625 & 0.209 & 0.11 & 0.044525 \\
$\mathrm{C}$ & 0.041 & 0.0205 & 0.0166 & 0.0116 & 0.0072 \\
$\mathrm{D}$ & \multicolumn{5}{c}{$17 \cdot 10^{4}$} \\
$\mathrm{E}$ & \multicolumn{5}{c}{8.98} \\
\hline
\end{tabular}

TABLE II

COEFFICIENTS FOR SHUNT REACTORS

\begin{tabular}{ccc}
\hline Location & $\mathrm{K}$ & $\mathrm{P}$ \\
\hline Onshore & 0.01049 & 0.8312 \\
Offshore & 0.01576 & 1.244 \\
Middle & 0.01576 & 12.44
\end{tabular}

\section{B. HVDC transmission system}

In this case, the HVDC system is modeled only to calculate total costs, Therefore, a simplified power flow formulation and cost functions are presented in the following subsections:

1) Power flow formulation: The HVDC system is modeled with a single-line diagram which includes converter stations and DC cables, as shown in Fig. ??. The converter stations represent the VSCs and associated transformers, while the DC cables are modeled as equivalent resistances for the positive and negative poles. Then, power losses of the HVDC transmission system in MW can be expressed as:

$P_{\text {loss }-D C}=\left(p_{\text {owf }}-p_{g}\right) \cdot S_{b}=\left(p_{\text {loss }-V S C}+p_{\text {loss }-c b}\right) \cdot S_{b}$

where $p_{\text {loss }-V S C}$ are the converter station power losses and $p_{l o s s-c b}$ the cable power losses, which are approximated as:

$$
\begin{aligned}
p_{\text {loss }-V S C} & \approx 2 p_{\text {owf }} 0.01 \\
p_{\text {loss }-c b} \approx 2 r_{d c} i_{d c}^{2} & =2 r_{d c}\left(\frac{p_{o w f}}{u_{D C-N}}\right)^{2}
\end{aligned}
$$

where $u_{D C-N}$ is the nominal DC voltage. It is observed that the VSC converter station power losses are assumed to be $1 \%$ of the generated power.

2) Cost modeling: Cost functions are presented for DC cables, converter stations, DC substation platform and power losses.

The cost of DC cables is presented in [12] as:

$$
C_{c b-D C}=\frac{\left(A+B P_{r-c b}+D\right) \cdot(9 n+1)}{10 E} \cdot l
$$

where $A, B, D$ and $E$ are coefficients defined in Table III which are dependent on the cable voltage, $P_{r-c b}$ is the rated power of the cable in $\mathrm{MW}$ and $l$ is the cable length in $\mathrm{km}$. 
The offshore and onshore converter stations are defined in the following equations [12]:

$$
\begin{gathered}
C_{\text {conv-off }}=42+27 \cdot \frac{P_{\text {conv-r }}}{300} \\
C_{\text {conv-on }}=18+27 \cdot \frac{P_{\text {conv-r }}}{300}
\end{gathered}
$$

where $P_{\text {conv }-r}$ is the rated power of the converter.

The cost of a DC substation platform is in average $250 \%$ higher than an equivalent $\mathrm{AC}$ option due to additional elements [15], [20], [7].

The operation cost of DC power losses is expressed as in (15), but considering $P_{\text {loss }-D C}$.

TABLE III

COEFFICIENTS FOR DC CABLES [13], [14]

\begin{tabular}{c|cccc}
\hline & $\pm 80 \mathrm{kV}$ & $\pm 150 \mathrm{kV}$ & $\pm 320 \mathrm{kV}$ & $\pm 525 \mathrm{kV}$ \\
\hline A & $-0.25179 \cdot 10^{6}$ & $-0.1 \cdot 10^{6}$ & $0.286 \cdot 10^{6}$ & $0.7454 \cdot 10^{6}$ \\
B & $0.03198 \cdot 10^{6}$ & $0.0164 \cdot 10^{6}$ & $0.00969 \cdot 10^{6}$ & $0.0061 \cdot 10^{6}$ \\
D & \multicolumn{4}{|c}{$22 \cdot 10^{6}$} \\
E & \multicolumn{4}{|c}{8.98} \\
\hline
\end{tabular}

\section{Offshore wind power plant}

OWPP is modeled considering different wind speeds, which are characterized following a Weibull distribution. Therefore, the probability of different wind speeds is expressed as [21]:

$$
p_{w}=\frac{k}{c}\left(\frac{v}{c}\right)^{k-1} \exp ^{-}\left(\frac{v}{c}\right)^{k}
$$

where $v$ is the wind speed, $c$ is the scale factor and $k$ is the shape factor. Typical values for offshore locations are $c=$ 9 [22]) and $k=2$ [23], which results in the Weibull distribution function shown in Fig. ??(a).

The OWPP is presented as a P-Q node for the power flow formulation, where $\mathrm{P}$ follows the power generation curve in Fig. ??(b). Also, it is assumed that the OWPP controller ensures that the total reactive power injection at the lowvoltage side of the offshore transformer is 0 , which follows the grid code in GB [24]. If the wind turbines were expected to absorb reactive power for compensation purposes, the transformer would need to be oversized accordingly.

\section{Methodology}

A methodology is presented in Fig. ?? for selecting the optimal voltage and defining location, size and number of reactors in an HVAC transmission system. This methodology is applied for a defined OWPP rated power $S_{o w f-N}$ and transmission cable length $l$. Also, the main grid parameters, $S C R$ and $X_{g} / R_{g}$, are included as inputs of the methodology.

Several HVAC transmission configurations are considered based on different voltage levels, $U_{i}$, and the reactor combinations, $C_{i}$, defined in Fig. ??. In particular, for a given $U_{i}$, cable and transformer parameters are calculated. Then, the cost of reactors and power losses is optimized for each configuration of $U_{i}$ and $C_{i}$ and considering OWPP operation under multiple wind speeds. As a result, the optimal solution is selected based on the total cost of each HVAC transmission configuration. Also, HVAC and HVDC are compared in terms of total cost in order to select the final offshore transmission system.

\section{A. Definition of cable and transformer parameters}

The HVAC cable parameters are obtained from data of manufacturers [25], considering the cable section $S$ and the given voltage $U_{i}$, while the transformer parameters are calculated from (5),(6) and (7) based on $U_{i}$ and $S_{o w f-N}$.

The cable section is also selected from data of manufacturers [25] using the rated current through the cables $I_{r-i}=S_{o w f-N} /\left(\sqrt{3} U_{i}\right)$. If $I_{r-i}$ exceeds the largest rated current available from manufacturers, a multiple number of cable circuits $N_{c b}$ is considered.

\section{B. Optimization definition}

The objective of the optimization is to minimize cost of power losses and reactors while complying with operational limits. Then, the optimization problem is expressed as:

$$
\begin{array}{cl}
F_{\text {obj }}(x)=C_{l o s s-o b j}(x)+C_{\text {react-obj }}(x) \\
\text { subject to } & h_{m}(x)=0, m \in[1, M] \\
& g_{n}(x) \leq 0, n \in[1, N]
\end{array}
$$

where $x$ is the variable vector, $F_{o b j}(x)$ is the objective function, $C_{l o s s-o b j}$ is the cost of power losses, $C_{r e a c t-o b j}$ is the reactor investment cost, $h_{m}(x)$ for $m \in[1, M]$ are the equality constraints and $g_{n}(x)$ for $n \in[1, N]$ are the inequality constraints.

The variable vector $x$ contains voltages and currents of all nodes in Fig. ??, admittances of added reactors for each wind speed range $j$ and maximum reactor values for all wind speeds. This vector is expressed as:

$$
\begin{gathered}
x=\left[x_{1}, \ldots, x_{j}, \ldots, x_{N_{w}}, \underline{Y}_{l-1}^{\max }, \ldots, \underline{Y}_{l-i}^{\max }, \ldots, \underline{Y}_{l-N_{\text {react }}}^{\max }\right] \\
x_{j}=\left[\underline{U}_{1 j}, \underline{U}_{2 j}, \underline{U}_{3 j}, \underline{U}_{4 j}, \underline{U}_{5 j}, \ldots\right. \\
\underline{I}_{1 j}, \underline{I}_{2 j}, \underline{I}_{3 j}, \underline{I}_{4 j}, \underline{I}_{5 j}, \underline{I}_{g j}, \ldots \\
\left.\underline{Y}_{l-1 j}, \ldots, \underline{Y}_{l-N_{\text {react }} j}\right] \\
i \in\left[1, N_{\text {react }}\right] ; \quad j \in\left[1, N_{w}\right]
\end{gathered}
$$

where $N_{w}$ is the number of wind speed ranges considered in the optimization, $Y_{l-i}^{\max }$ is the maximum value of reactor $i$ for all wind speeds and $N_{\text {react }}$ is the number of reactors.

The cost functions are defined as:

$$
\begin{gathered}
C_{\text {loss-obj }}=8760 \cdot t_{\text {owf }} \cdot C_{E} \cdot \sum_{j=1}^{N_{w}}\left(P_{\text {loss }-j} \cdot p_{w-j}\right) \\
C_{\text {react-obj }}=\sum_{i=1}^{N_{\text {react }}}\left(Y_{l-i}^{\max } \cdot K+P\right)
\end{gathered}
$$

where $P_{\text {loss }-j}$ are the power losses in (9) at wind speed range $j$ and $p_{w-j}$ is the probability of wind speed range $j$.

The equality constraints $h_{m}(x)$ are obtained from the power flow equations in (8) and for each wind speed range $j$. The inequality constraints $g_{n}(x)$ are defined based on limits for voltage, current, reactive power and reactor values. However, these limits can be also defined based on grid code require- 
ments. The lower and upper limits of currents and voltages are expressed as:

$$
\begin{gathered}
U_{\min } \leq U_{k j} \leq U_{\max } ; \quad I_{k j} \leq I_{\max } \\
k \in[1,5] ; \quad j \in\left[1, N_{w}\right]
\end{gathered}
$$

where $U_{\min }$ and $U_{\max }$ are the minimum and maximum voltage limits and $I_{\max }$ is the maximum current limit. It is assumed that the voltage operational limits are set to $\pm 10 \%$ of the nominal value, while the maximum current is $10 \%$ of the cable rated value.

The reactive power delivered to the grid $Q_{g j}$ is also limited as follows:

$$
Q_{\min } \leq Q_{g j} \leq Q_{\max }, \quad j \in\left[1, N_{w}\right]
$$

where $Q_{\min }$ and $Q_{\max }$ are the minimum and maximum reactive power values. In this case, the maximum reactive power is set to $0, Q_{\min }=Q_{\max }=0$, but in general this can be also defined by grid code requirements.

The reactors are limited by the maximum values defined in the variable vector $x$ :

$$
\begin{gathered}
Y_{l-i j} \leq Y_{l-i}^{\max } \\
i \in\left[1, N_{\text {react }}\right] ; \quad j \in\left[1, N_{w}\right]
\end{gathered}
$$

It is observed that these reactor constraints are used to obtain the maximum reactor value for all wind speed conditions. The purpose of this methodology is to provide values that could be later evaluated by manufacturers as realistic. The upper limit for $Y_{l-i}^{\max }$ is 0 , as it is defined negative in III-A3, while the lower limit is mainly limited by the optimization itself as it is directly impacting the objective function.

The optimization is implemented in MATLAB using the function fmincon, which is suitable to solve non-linear problems. In particular, interior-point and SQP were selected as specific algorithms for the optimization problem. The computational performance for each combination of rated power and transmission distance depends on the time required for finding feasible solutions, which varies from 45 to $140 \mathrm{~s}$ in conventional desktop computer (i7-7500U, $2.9 \mathrm{GHz}, 16$ GB RAM). However, other algorithms and software could be also used to implement the optimization problem of the methodology in Fig. 9. and reduce the computation time [26] [28].

\section{ANALYSIS OF OFFSHORE TRANSMISSION CONFIGURATIONS}

In this Section, offshore transmission configurations are compared in terms of total costs and specific case studies are presented to analyze costs and selection of optimal configurations in detail. Values of system parameters are summarized in Table IV of Appendix.

\section{A. Cost comparison}

The methodology presented in Section IV is used to identify the range of OWPP rated powers and distances where different offshore transmission configurations are selected based on total cost.
The selection between HVAC and HVDC transmission systems is presented in Fig. ??(a). The results are presented for OWPP rated powers between $100 \mathrm{MW}$ and $2500 \mathrm{MW}$ with a variation of $100 \mathrm{MW}$ and for distances between $25 \mathrm{~km}$ and 220 $\mathrm{km}$ with a variation of $5 \mathrm{~km}$. It is observed that for high rated powers the break-even distance between HVAC and HVDC is around $150 \mathrm{~km}$. As shown in early literature, the break distance was around $80 \mathrm{~km}$ [13], but with the introduction of mid-cable reactor compensation, this distance is increased up to around $120-160 \mathrm{~km}$ [7] which agrees with the results of this paper.

Also, the distance ranges for selecting number of reactors for HVAC configurations are identified as shown in Fig. ??(b). One reactor is selected for a distance up to $30-45 \mathrm{~km}$, while two reactors are preferred up to around $70-80 \mathrm{~km}$, except for low powers where this distance is increased.

It should be mentioned that for low rated powers, the selection of the transmission system can be influenced by the cost of the power losses and reactors, which are obtained from the optimization in Section IV-B. As a result, the break-even distance does not show a clear trend and $150 \mathrm{kV}$ could be selected as optimal voltage.

\section{B. Case studies}

Two case studies are analyzed in this Section. The first case study is based on the project Hornsea 3, which has a planned rated power of $2400 \mathrm{MW}$ and a distance from shore of 120 $\mathrm{km}$ [1]. The selected configuration corresponds to an HVAC transmission system of $220 \mathrm{kV}$ and three reactors, as seen in Fig.??.

As part of the methodology in Section IV, the cost of power losses and reactors is optimized leading to the results shown in Fig. ??, where combinations are grouped according to the number of reactors. The optimal combination is $C_{13}$, which corresponds to an optimal voltage of $220 \mathrm{kV}$ and reactors located at the offshore wind farm, the middle of the cable and the onshore grid. It is observed that installing more than one reactor shows a significant cost reduction around 300 $\mathrm{M} €$, while installing three reactors instead of two results in a cost reduction around 40-90 $\mathrm{M} €$. In particular, combinations with a reactor located at the middle of the cable contributes to a further decrease of approximately $50 \mathrm{M} €$. Also, a cost difference of $100 \mathrm{M} €$ is observed between voltage levels.

Aside from cost comparisons, the optimization in Section IV-B ensures that voltages and currents in every node are within the limits defined in (27) for different wind powers, as seen in Fig. ??(a) and (b). Also, reactive power compensated by the reactors is presented in Fig. ??(c), which results in the following range of values for each reactor location:

$$
\begin{gathered}
0.48 \leq Q_{m d} \leq 0.57 ; \quad 0.18 \leq Q_{o f f} \leq 0.26 \\
0.25 \leq Q_{o n} \leq 0.28
\end{gathered}
$$

where the equivalent reactor admittances are equal to the compensated reactive powers, since the system is analyzed in p.u. It is observed that maximum reactive power compensation is required for low wind generation.

The selected HVAC configuration must include the investment and installation cost of the system, as shown in Fig. ??, 
where $C_{13}$ with $220 \mathrm{kV}$ is still the configuration with the lowest total cost. It is observed that the final cost of the system is primarily dependent of the cable cost, representing up to $60 \%$ of the total cost when $110 \mathrm{kV}$ is used. In particular, the cable cost is affected by the number of cable circuits, which is defined from the voltage level. This results in a cost reduction of approximately $1000 \mathrm{M} €$ between 110 and $220 \mathrm{kV}$.

The final offshore transmission system is selected based on the total cost comparison between HVAC and HVDC configurations, as shown in Fig. ??(a). In this case, HVDC configuration is $17 \%$ more expensive than the HVAC option. It is clear that the highest cost in HVAC corresponds to the cable cost (46\% of total cost), while in HVDC this corresponds to the substation cost (58\% of total cost), mainly due to the converter. Also, it is observed that reactive power compensation represents a small proportion of the total cost.

In addition, the possibility to include a variable tap changer in the onshore transformer is analyzed. Fig. ?? evaluates the impact that different tap changer values have on the total cost. In particular, a normalized transformer ratio $\tau=1$ presents the initial value used in the previous analysis. It is observed that a tap changer variation of $5 \%$ results in a cost variation below $2 \%$, therefore a different setting of the transformer ratio could have a minor impact on the final selection between HVAC and HVDC transmission system.

The second case study represents a system with OWPP rated power of $100 \mathrm{MW}$ and distance from shore equal to $100 \mathrm{~km}$, where the optimization of power losses and reactor cost has an influence on the selection of the HVAC configuration.

The optimal combination is $C_{5}$, as shown in Fig.??, which corresponds to an optimal voltage of $150 \mathrm{kV}$ and reactors located at the offshore wind farm and the onshore side of the cable. It is observed that combinations including the midcable reactor show a higher cost. Also, combinations with 220 $\mathrm{kV}$ might be more expensive than $150 \mathrm{kV}$. This is because a low OWPP rated power is considered for this second case study, defining the same number of cable circuits $\left(N_{c b}=1\right)$ independently of the voltage level. As a result, cost of the power losses increases for options with higher voltages due to smaller cable sections.

The selected HVAC configuration after including investment and installation costs remains as combination $C_{5}$ with $150 \mathrm{kV}$, as shown in Fig.??. In this case, substation and cable costs are similar for all voltage levels, since the number of cable circuits is the same. Therefore, the optimal cost for power losses and reactors determines the HVAC configuration. The HVAC configuration is finally selected over the equivalent HVDC configuration, as shown in Fig. ??(b), where cable cost is similar for both configurations.

\section{Sensitivity analysis}

The comparison between HVAC and HVDC transmission system can be further analyzed with a sensitivity analysis that includes components with a significant impact in the total cost. In particular, the HVAC cables, the converter and the power losses are identified as the main cost components from the previous analysis. First, HVAC cable and converter cost variation are analyzed in Fig. ?? and ??, where three rated powers of OWPP (100, 1000 and $2500 \mathrm{MW})$ are considered along with a distance range from 25 to $220 \mathrm{~km}$. In general, the break-even distance only varies few tenths of kilometers. For $100 \mathrm{MW}$ and converter cost reduction, the break-even distance varies for around $30 \mathrm{~km}$, while for $1000 \mathrm{MW}$ and $2500 \mathrm{MW}$, the change is between 10 and $15 \mathrm{~km}$. On the other hand, by modifying the cost of HVAC cable, the intersection shifts for around $25 \mathrm{~km}$ in all cases.

Next, the impact of the power losses cost is analyzed based on the cost of energy and the lifetime of the OWPP, as shown in Fig. ?? and ??. It is observed that for lower powers, the influence of power losses cost is more significant. This is because a low number of cables is used, which do not have a large contribution on the total cost. Therefore, the break-even distance varies from around $5 \mathrm{~km}$ (high rated powers) to 50 $\mathrm{km}$ (low rated powers).

\section{CONCLUSION}

In this paper, the contribution of a mid-cable reactor in an HVAC offshore transmission system for OWPP is analyzed in detail. The introduction of such mid-cable reactor can reduce the total cost and extend the break-even distance between HVAC and HVDC transmission configurations.

Therefore, a methodology is presented to design an HVAC transmission system for specific OWPP rated powers and distances from shore. The cost of power losses and reactive power compensation are optimized for multiple wind speed conditions. As a result, this methodology selects the optimal HVAC voltage and provides the location, size and number of reactors. Also, the HVAC configuration is compared with an equivalent HVDC configuration in order to select the final offshore transmission system based on total cost.

The results conclude that using three reactors including a mid-cable reactor could be a potential solution for high OWPP rated powers and for a distance range from $70 \mathrm{~km}$ up to $150 \mathrm{~km}$. However, the cost reduction of HVAC cables and converters and the considerations in the cost of energy and lifetime of the OWPP can change the break-even distance in the range of tenths of kilometers. It is also seen that from the analyzed voltages, $220 \mathrm{kV}$ is the most favorable solution. Therefore, high voltages are preferred, since a reduced number of cable circuits is used, except for low OWPP rated powers, where the cost of power losses and reactors can determine the voltage selection.

\section{APPENDIX}

Values of system parameters are presented in Table IV.

\section{BIBLIOGRAPHY}

[1] RenewableUK, "Offshore Wind Project Timelines," RenewableUK, London, United Kingdom, Tech. Rep., 2016.

[2] J. Hjerrild, S. Sahukari, M. Juamperez, Ł. H. Kocewiak, M. A. Vilhelmsen, J. Okholm, M. Zouraraki, and T. Kvarts, "Hornsea Projects One and Two - Design and Execution of the Grid Connection for the World's Largest Offshore Wind Farms," in CIGRE Symposium, Aalborg, Denmark, Jun. 2019, pp. 1-11. 
TABLE IV

SYSTEM PARAMETERS

\begin{tabular}{ccc}
\hline Variable & Definition & Value \\
\hline$S C R$ & Short circuit ratio & 5 \\
$X_{g} / R_{g}$ & $\begin{array}{c}\text { Ratio of the system reactance } \\
\text { to the system resistance }\end{array}$ & 10 \\
$t_{\text {owf }}$ & Life time of the OWPP & 30 years \\
$C_{E}$ & Cost of energy & $100 € / \mathrm{MWh}$ \\
$P_{C u}^{\text {loss }}$ & Copper losses & $60 \mathrm{~kW}$ \\
$P_{F e}^{l o s s}$ & Iron losses & $40 \mathrm{~kW}$ \\
$u_{k}$ & Short circuit voltage & $18 \%$ \\
$i_{o}$ & Open circuit current & $1.2 \%$ \\
\hline
\end{tabular}

[3] W. Wiechowski and P. B. Eriksen, "Selected studies on offshore wind farm cable connections - challenges and experience of the Danish TSO," in IEEE Power and Energy Society 2008 General Meeting: Conversion and Delivery of Electrical Energy in the 21st Century, PES, 2008.

[4] J. Carolan, J. Brack, K. Bell, and H. Roberts, "HornSea Project Three Offshore Wind Farm - Preliminary Environmental Information Report:Chapter 3, Project Description,” DONG Energy Power (UK) Ltd., London, United Kingdom, Tech. Rep., 2017.

[5] T. Miller, Reactive Power Control in Electric Systems. New York, NY, USA: Wiley, 1982.

[6] Z. Chen, D. Xiaowei, and Z. Guiping, "Optimisation of reactive power compensation of HVAC cable in off-shore wind power plant," IET Renewable Power Generation, vol. 9, no. 7, pp. 857-863, 2015.

[7] D. Elliott, K. R. W. Bell, S. J. Finney, R. Adapa, C. Brozio, J. Yu, and $\mathrm{K}$. Hussain, "A comparison of AC and HVDC options for the connection of offshore wind generation in Great Britain," IEEE Transactions on Power Delivery, vol. 31, no. 2, pp. 1-12, 2016.

[8] A. R. Henderson, L. Greedy, F. Spinato, and C. A. Morgan, "Optimising Redundancy of Offshore Electrical Infrastructure Assets by Assessment of Overall Economic Cost," in European Offshore Wind Energy Conference, Stockholm, Sweden, Jun. 2009, pp. 1-13.

[9] D. Van Hertem, O. Gomis-Bellmunt, and J. Liang, HVDC Grids: for offshore and supergrid of the future, 2016.

[10] ABB, "525 kV extruded HVDC cable system: Doubling power transmission over longer distances," ABB, Karlskrona, Sweden, Tech. Rep., 2014.

[11] J. Machowski, J. W.Bialek, and J. R.Bumby, Power System Dynamics, Stability and Control, 2012

[12] H. Ergun, D. Van Hertem, and R. Belmans, "Transmission System Topology Optimization for Large-Scale Offshore Wind Integration HE European Union has set ambitious goals regarding," IEEE Transactions on Sustainable Energy, vol. 3, no. 4, pp. 908-917, 2012.

[13] B. Van Eeckhout, D. Van Hertem, M. Reza, K. Srivastava, and R. Belmans, "Economic comparison of VSC HVDC and HVAC as transmission system for a 300MW offshore wind farm," European Transactions on Electrical Power, vol. 20, no. 5, pp. 661-671, 2010.

[14] S. Lundberg, "Performance comparison of wind park configurations," Chalmers University of Technology, Goteborg, Sweden, Tech. Rep. 30R, 2003.

[15] Regional Group North Sea, "Offshore Transmission Technology," ENTSO-E AISBL, Brussels, Belgium, Tech. Rep., 2011.

[16] L. P. Lazaridis, "Economic Comparison of HVAC and HVDC Solutions for Large Offshore Wind Farms under Special Consideration of Reliability," Electrical Engineering, vol. 12, no. 4, pp. 203-208, 2005.

[17] X. Xiang, M. M. C. Merlin, and T. C. Green, "Cost Analysis and Comparison of HVAC, LFAC and HVDC for Offshore Wind Power Connection," in IET 12th International Conference on AC and DC Transmission, Beijing, China, May 2016, pp. 1-6.

[18] M. Dicorato, G. Forte, M. Pisani, and M. Trovato, "Guidelines for assessment of investment cost for offshore wind generation," Renewable Energy, vol. 36, no. 8, pp. 2043-2051, 2011.

[19] Ørsted, "Hornsea Project Two Offshore Wind Farm-Decommissioning Programme,” Ørsted, Fredericia, Denmark, Tech. Rep., 2019.

[20] P. Djapic and G. Strbac, "Cost Benefit Methodology for Optimal Design of Offshore Transmission Systems," Centre for Sustainable Electricity and Distributed Generation, 2008.

[21] T. Ackermann, Wind Power in Power Systems. Hoboken, NJ, USA: Wiley, 2005.

[22] L. Li, Z. Gao, and T. Moan, "Joint Environmental Data At Five European Offshore Sites for design of combined wind and wave energy devices," in 32nd International Conference on Ocean, Offshore and Artic Engineerin, Nantes, France, Jun. 2013, pp. 1-12.

[23] T. Burton, D. Sharpe, N. Jenkins, and E. Bossanyi, Wind Energy Handbook, 2001.

[24] National Grid Electricity System Operator Limited, "The Grid codeNational Grid," Tech. Rep. 5, 2019.

[25] ABB, "Submarine Cable Systems: Attachment to XLPE Land Cable Systems-Users Guide,” ABB, Karlskrona, Sweden, Tech. Rep., 2010.

[26] Á. Lorca and X. A. Sun, "The adaptive robust multi-period alternating current optimal power flow problem," IEEE Transactions on Power Systems, vol. 33, no. 2, pp. 1993-2003, 2018.

[27] X. Bai, L. Qu, and W. Qiao, "Robust ac optimal power flow for power networks with wind power generation," IEEE Transactions on Power Systems, vol. 31, no. 5, pp. 4163-4164, 2016.

[28] R. A. Jabr, "Adjustable robust opf with renewable energy sources," IEEE Transactions on Power Systems, vol. 28, no. 4, pp. 4742-4751, 2013.

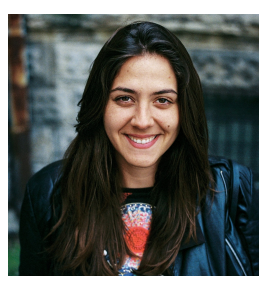

Jovana Dakic received her M.S. degree in electrical engineering from School of Electrical Engineering, University of Belgrade, Belgrade, Serbia, in 2017. She is working towards a Ph.D. degree in electrical engineering as an early-stage researcher as part of InnoDC (Innovative tools for offshore wind and DC grids) project at CITCEA-UPC research group, Technical University of Catalonia (UPC), Barcelona, Spain. Her research interests include collection grids and transmission systems for connections of offshore wind power plants.

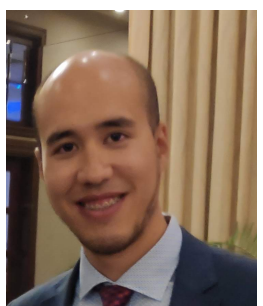

Marc Cheah-Mane (S'14-M'18) received the degree in industrial engineering from the School of Industrial Engineering of Barcelona (ETSEIB), Technical University of Catalonia (UPC), Barcelona, Spain, in 2013, and the $\mathrm{PhD}$ degree in electrical engineering from Cardiff University, Cardiff, the U.K. in 2017. From 2017 to 2020 he was a research associate in CITCEA-UPC research group, Barcelona, Spain. Since March 2020 he is a Serra Hunter Lecturer at the Electrical Engineering Department of UPC. His research interests include power electronics, high-voltage direct current systems, wind and photovoltaic generation.

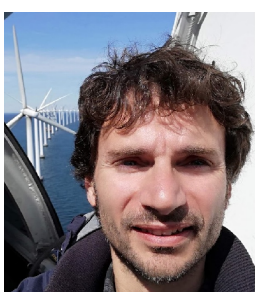

Oriol Gomis-Bellmunt (S'05-M'07-SM'12) received the degree in industrial engineering from the School of Industrial Engineering of Barcelona (ETSEIB), Technical University of Catalonia (UPC), Barcelona, Spain, in 2001 and the Ph.D. degree in electrical engineering from the UPC in 2007. In 1999, he joined Engitrol S.L. where he worked as Project Engineer in the automation and control industry. Since 2004, he has been with the Electrical Engineering Department, UPC where he is a Professor and participates in the CITCEA-UPC research group. Since 2020, he is an ICREA Academia researcher. His research interests include the fields linked with electrical machines, power electronics, and renewable energy integration in power systems. 


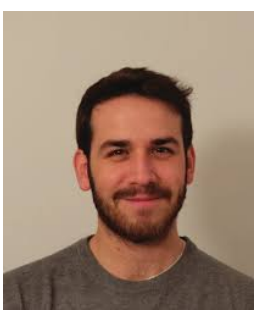

Eduardo Prieto-Araujo (S'12-M'16) received the degree in industrial engineering from the School of Industrial Engineering of Barcelona (ETSEIB), Technical University of Catalonia (UPC), Barcelona, Spain, in 2011 and the Ph.D. degree in electrical engineering from the UPC in 2016. He joined CITCEA-UPC research group in 2010 and currently he is a Serra Húnter Lecturer with the Electrical Engineering Department, UPC. His main interests are renewable generation systems, control of power converters for HVDC applications, interaction analysis between converters, and power electronics dominated power systems. 